\title{
Using a detachable snare, the cowboy method, to troubleshoot stent dysfunction after endoscopic ultrasound-guided hepaticogastrostomy
}

Endoscopic ultrasound (EUS)-guided biliary drainage, such as by EUS-guided choledochoduodenostomy (EUS-CDS) or EUS-guided hepaticogastrostomy (EUSHGS), is a popular technique. Recently, these techniques have been used not only as alternative methods of drainage but also for primary drainage $[1,2]$. Therefore, it is necessary to prevent and troubleshoot adverse events. A stent that is placed from the stomach may sometimes deviate into the esophagus after EUS-HGS, causing severe reflux esophagitis with the secretion of bile. Herein, we report a unique and effective management of this adverse event.

A 42-year-old man with recurrence of peritoneal dissemination after surgery to treat a parotid gland cancer was admitted with vomiting and obstructive jaundice. Computed tomography (CT) scanning revealed stenosis of the second portion of the duodenum and dilatation of the bile duct, with stenosis of the lower bile duct. We therefore placed a duodenal stent and EUS-HGS was performed to achieve primary drainage. The intrahepatic bile duct (B2) was punctured from the stomach, and a $6-\mathrm{mm} \times 12-\mathrm{cm}$ fully covered metal stent (Hanarostent; Boston Scientific, Japan) was placed (> Fig.1). On day 2, he vomited bile juice several times. Radiography, including a further CT scan, revealed that the oral side of the stent had deviated into the esophagus (> Fig. 2).

Initially, we redirected the stent in the stomach using a cap-fitted gastroscope. Thereafter, we considered fixing the stent to the stomach wall to avoid recurrence; however, fixing the stent to the stomach directly could have caused it to dislocate. We therefore used a detachable snare to hold the HGS stent, clipping the string of the detachable snare to the stomach ( $>$ Video $1 ;>$ Fig. 3 ). Fixing the string provided extra space, which we be-
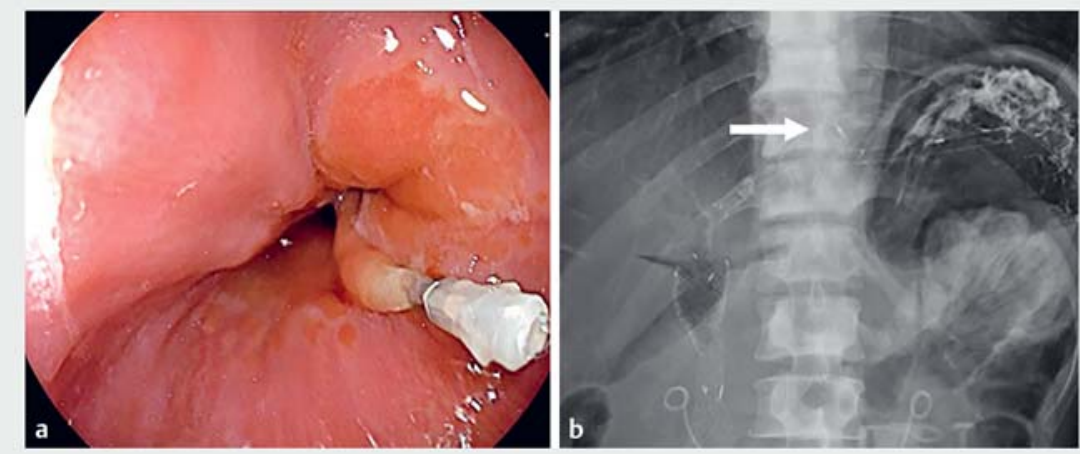

- Fig. 1 Images from the endoscopic ultrasound-guided hepaticogastrostomy (EUS-HGS) showing: $\mathbf{a}$ an endoscopic view of the gastroesophageal junction clipped prior to EUS-HGS to prevent transesophageal EUS-HGS; $\mathbf{b}$ a radiographic image of the fully covered metal stent placed via the stomach and deployed under the clip.
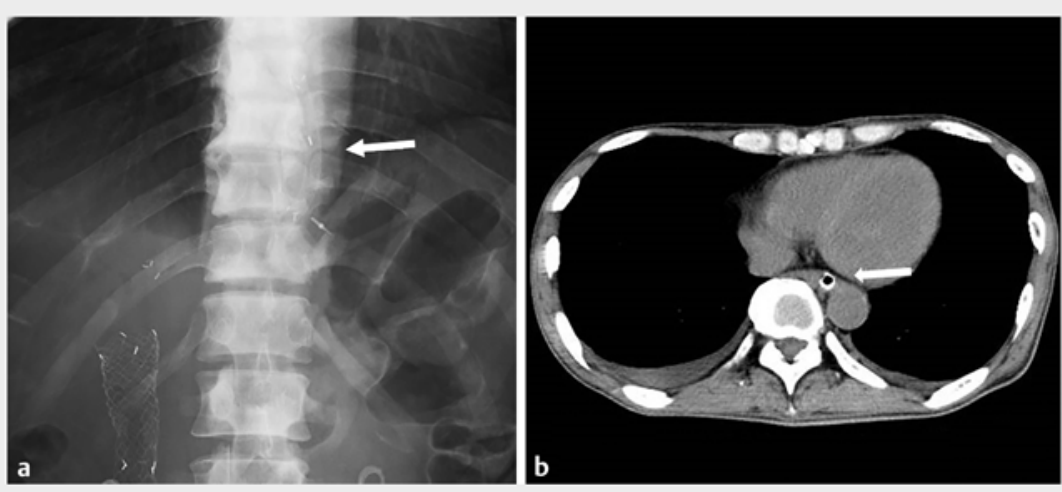

- Fig. 2 Further imaging on day 2 showing deviation of the oral side of the stent toward the esophagus on: a radiographic image; $\mathbf{b}$ computed tomography image.

lieved would prevent stent dislocation, despite movement of the stomach.

Following this procedure, the patient was asymptomatic and showed no recurrence (\$Fig.4). This management can be easily performed and can prevent recurrence of stent deviation into the esophagus.

Endoscopy_UCTN_Code_CPL_1AL_2AD
Competing interests

The authors declare that they have no conflict of interest.

The authors

Nozomi Okuno, Kazuo Hara, Nobumasa Mizuno, Shin Haba, Takamichi Kuwahara, Hiroki Koda, Akira Miyano Department of Gastroenterology, Aichi Cancer Center, Nagoya, Japan 


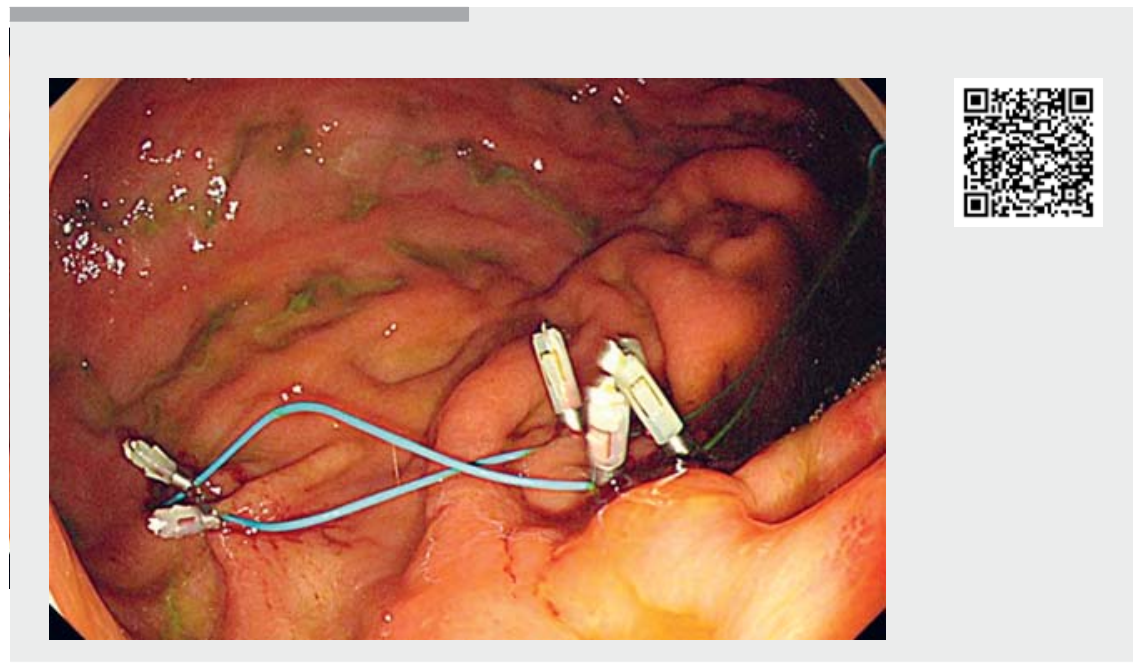

$\checkmark$ Video 1 The cowboy method of fixing an endoscopic ultrasound-guided hepaticogastrostomy stent to the stomach wall using a detachable snare to prevent repeat deviation of the stent into the esophagus.
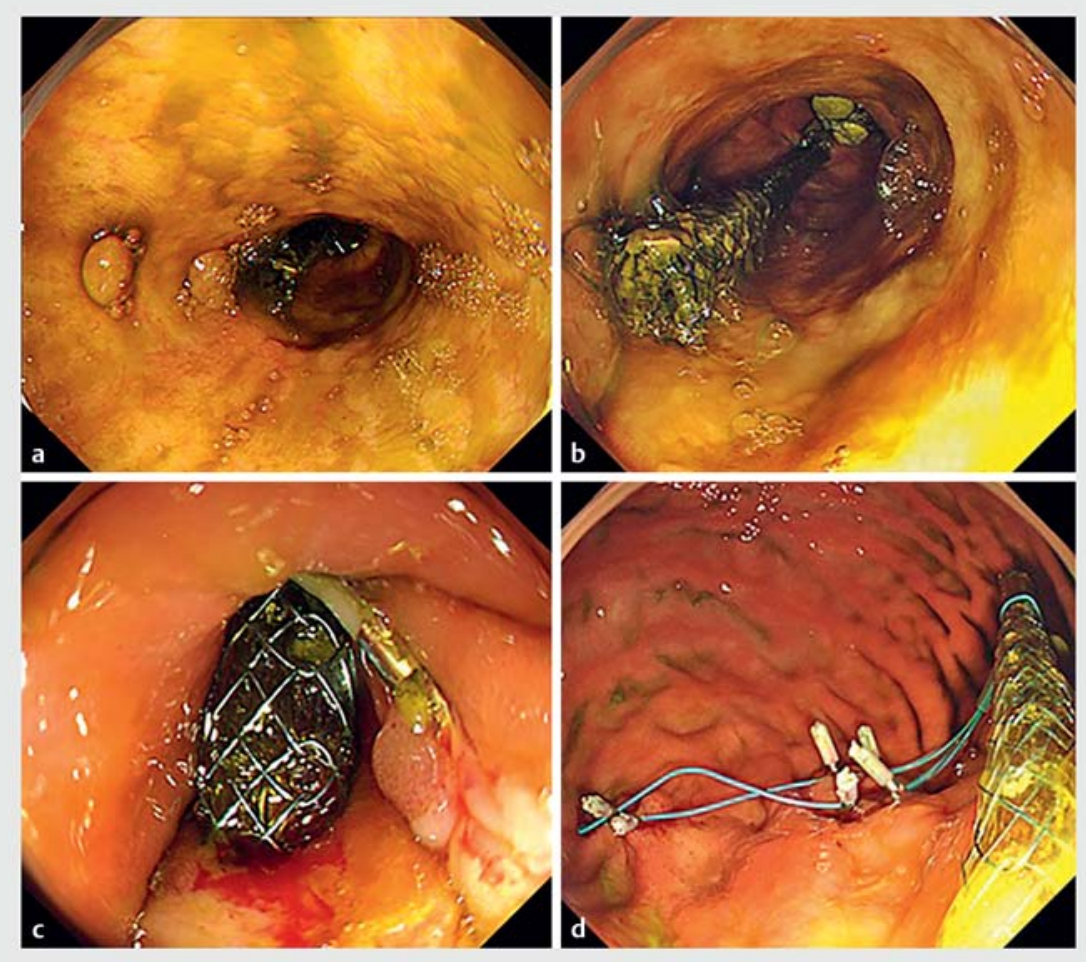

- Fig. 3 Gastroscopic images showing: a severe reflux esophagitis with bile secretion; $\mathbf{b}$ the oral side of the stent that had deviated into the esophagus; $\mathbf{c}$ the stent redirected into the stomach using a gastroscope; $\mathbf{d}$ the hepaticogastrostomy stent fixed to the stomach wall using a detachable snare.

\section{Corresponding author}

\section{Kazuo Hara, MD}

Department of Gastroenterology, Aichi Cancer Center, Kanokoden, Chikusa-ku, Nagoya, Aichi 464-8681, Japan

Fax: +81-52-7635233

khara@aichi-cc.jp

\section{References}

[1] Hara K, Yamao K, Hijioka S et al. Prospective clinical study of endoscopic ultrasoundguided choledochoduodenostomy with direct metallic stent placement using a forward-viewing echoendoscope. Endoscopy 2013; 45: 392-396

[2] Okuno N, Hara K, Mizuno N et al. Efficacy of the 6-mm fully covered self-expandable metal stent during endoscopic ultrasoundguided hepaticogastrostomy as a primary biliary drainage for the cases estimated difficult endoscopic retrograde cholangiopancreatography: A prospective clinical study. J Gastroenterol Hepatol 2018; 33: 14131421 

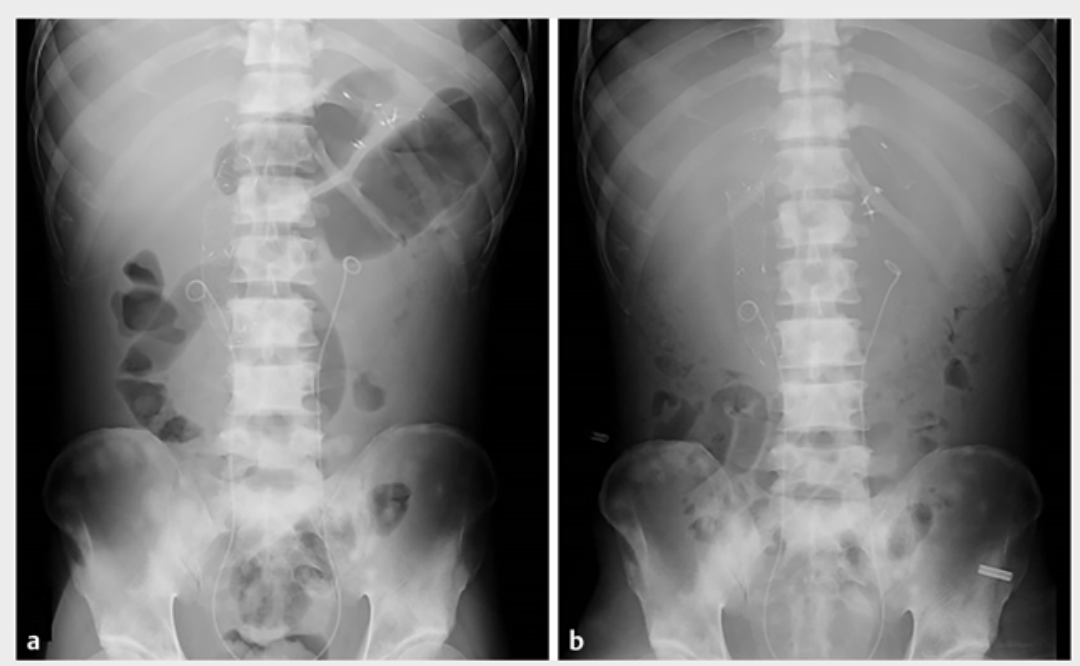

- Fig.4 Radiographic images showing the position of the hepaticogastrostomy stent, which is different but still seen in the stomach, after: a 4 weeks; $\mathbf{b} 6$ weeks.

\section{Bibliography}

DOI https://doi.org/10.1055/a-1076-9655

Published online: 20.12.2019

Endoscopy 2020; 52: E232-E234

(C) Georg Thieme Verlag KG

Stuttgart $\cdot$ New York

ISSN 0013-726X

\section{ENDOSCOPY E-VIDEOS \\ https://eref.thieme.de/e-videos}

回回 Endoscopy E-Videos is a free y access online section, reporting 回制: on interesting cases and new techniques in gastroenterological endoscopy. All papers include a high quality video and all contributions are freely accessible online.

This section has its own submission website at

https://mc.manuscriptcentral.com/e-videos 